CLINICAL STUDY

\title{
Orexin-A and leptin change inversely in fasting non-obese subjects
}

\author{
Gen Komaki ${ }^{1,2}$, Yoshiaki Matsumoto ${ }^{2}$, Hiroaki Nishikata ${ }^{2}$, Keisuke Kawai $^{2}$, Takehiro Nozaki ${ }^{2}$, Masato Takii $^{2}$, \\ Hiroshi Sogawa ${ }^{2}$ and Chiharu Kubo ${ }^{2}$ \\ ${ }^{1}$ Division of Psychosomatic Research, National Institute of Mental Health, National Center of Neurology and Psychiatry, Ichikawa, Japan and \\ ${ }^{2}$ Department of Psychosomatic Medicine, Graduate School of Medical Sciences, Kyushu University, Fukuoka, Japan \\ (Correspondence should be addressed to G Komaki, Division of Psychosomatic Research, National Institute of Mental Health, NCNP, 1-7-3 Kohnodai, \\ Ichikawa City, Chiba 272-0827, Japan; Email: komaki@ncnp-k.go.jp)
}

\begin{abstract}
Objective: Leptin, neuropeptide-Y (NPY) and orexin are peptides regulating energy metabolism and appetite control. NPY and orexin are mainly found in the central nervous system and they have also recently been found in the peripheral nervous system. We investigated how fasting affects changes in circulating concentrations of these peptides and their association with nutritional and metabolic parameters in humans.

Design and methods: Ten non-obese female patients with psychosomatic disorders fasted for 7 or 10 days. Blood samples were collected at $0800 \mathrm{~h}$ before fasting, on the $3 \mathrm{rd}$ and 7 th days during the fast (with an additional sample taken on the 10th day when the fasting continued for 10 days) and on the 3rd and 7th days of refeeding. We measured blood concentrations of orexin-A, NPY, leptin, adrenocorticotropin, cortisol, insulin, C-peptide, glucose, and $\beta$-hydroxybutyrate.

Results: Body mass index and plasma leptin concentrations concomitantly and significantly decreased during fasting, whereas serum orexin-A concentrations significantly increased and were negatively correlated with plasma leptin concentrations. Plasma NPY concentrations decreased slightly but were not significantly different from the prefasting values, and no significant relationship with leptin or orexin-A was found. Orexin-A and leptin concentrations showed a significant inverse correlation with serum glucose, insulin, C-peptide, and $\beta$-hydroxybutyrate concentrations. Only changes in plasma leptin concentrations showed a significant negative correlation with serum cortisol concentrations. All the measured indices which changed during fasting returned to the prefasting concentrations by the 7 th day of refeeding.

Conclusion: Peripheral orexin-A and leptin concentrations inversely change during fasting, which is significantly correlated with energy metabolism in humans.
\end{abstract}

European Journal of Endocrinology $144645-651$

\section{Introduction}

Fasting therapy was at first mainly used for the treatment of obesity (1) and since the 1970s this therapy has also been found to be one of the effective treatments for psychosomatic disorders (2). The precise mechanism(s) underlying the psychological and physiological changes during fasting remains unclear; however, there is indirect evidence that such an effect may be mediated by alterations in the hypothalamicpituitary-adrenal (HPA) axis and/or metabolic and energy homeostasis (3-5), as indicated in acute mental and environmental stresses $(6,7)$.

Recently, peptides such as orexin, neuropeptide Y (NPY) and leptin have been found to play an important role in the regulation of energy metabolism (8-10). The mechanisms by which they interact with each other (11-13) and with other nutritional and metabolic factors including insulin and cortisol $(8,14)$ have been investigated in animals. In humans, on the other hand, the changes in circulating levels of leptin and NPY in response to various nutritional states such as fasting (15-17) and to psychological and/or physical stresses (18-20) were studied; however, changes in orexin concentrations have not yet been investigated. Interestingly, orexin-containing neurones were recently found in the gut that expressed a functional change in response to energy status (21). Although changes in circulating levels of these peptides in the periphery in response to fasting cannot be assumed to have any relationship to those in the central nervous system, it seems important to investigate if these peptides are of physiological importance and how they are regulated in the periphery during fasting in humans. 
Therefore, we investigated the effect of total fasting on peripheral orexin, NPY, and leptin concentrations and their interrelations and determined the relationships of those neuropeptides with other hormonal and metabolic factors in non-obese subjects.

\section{Subjects and methods}

\section{Subjects and fasting therapy protocol}

Ten female hospitalized patients aged 14-49 years (average age $26.2 \pm 3.7$ (s.E.M.) years) with irritable bowel syndrome $(n=5)$, atopic dermatitis $(n=2)$, non-ulcer dyspepsia $(n=1)$, bronchial asthma $(n=1)$, and nervous cough $(n=1)$ underwent fasting therapy. These patients met the guidelines for the use of fasting therapy for the treatment of psychosomatic disorder (2). No endocrine, metabolic, liver or kidney diseases were evident in these patients, and none suffered from any psychotic disorders such as schizophrenia or major affective disorders. As previously described $(5,22)$, after more than a one-month hospital stay on a daily diet of 8.37-9.20 MJ (2000-2200 kcal) of mixed food, these patients gave informed consent according to the Declaration of Helsinki and began total fasting therapy. All patients were required to fast for 7 or 10 days except for free daily water intake in addition to the intravenous administration of $500 \mathrm{ml}$ fluid containing $21.5 \mathrm{~g}$ glucose and electrolyte to prevent dehydration during fasting. After fasting, refeeding was started with a mixed diet, gradually increasing from $0.42 \mathrm{MJ}$ on day 1 (3 g carbohydrate, $2 \mathrm{~g}$ protein, $1 \mathrm{~g}$ fat) to $8.37 \mathrm{MJ}$ on day 7 ( $280 \mathrm{~g}$ carbohydrate, $80 \mathrm{~g}$ protein, $65 \mathrm{~g}$ fat) of mixed food. No patient was taking any medication prior to or during their fast. During the study, the patients were kept under constant medical surveillance.

\section{Blood collection and preparation}

Peripheral blood samples were taken at $0800 \mathrm{~h}$ before and on the 3rd and 7th fasting days, by venipuncture of an antecubital vein, with an additional sample taken on the 10th day when the fasting continued for 10 days, as previously reported (5). Blood samples were also taken on the 3rd and 7th days of the recovery period. Blood was collected into tubes containing EDTA-2Na for plasma NPY, leptin, and adrenocorticotropin (ACTH) analysis. Serum samples were collected in clotting tubes for orexin-A, cortisol, C-peptide, insulin, glucose, and $\beta$-hydroxybutyrate $(\beta-\mathrm{OH}$-butyrate) determination.

\section{Assays}

Serum glucose was measured by standard techniques for the oxidase method with the Beckman Glucose Analyzer II (Brea, CA, USA) in the central laboratory of our hospital. Serum $\beta-\mathrm{OH}$-butyrates were measured by an enzyme assay method with the Hitachi Autoanalyzer 7170 (Hitachi Seisakusho, Hitachi). Plasma ACTH was assessed using an immunoradiometric assay kit (Nichols Institute, San Juan Capistrano, CA, USA) based on the avidin-biotin separation method. Serum cortisol concentration was determined in duplicate by a fluorescence polarization immunoassay using the Abbott TDx cortisol kit and an Abbott TDx autoanalyzer (Abbot Diagnostics, Maidenhead, Berks, UK). Serum C-peptide concentration was determined with a radioimmunoassay kit (Shionogi Pharmaceutical Co, Osaka, Japan). Serum insulin was determined with a Phadeseph radioimmunoassay kit (SD-8566, Shionogi Pharmaceutical Co.).

There are two homologous orexin peptides, orexin-A and orexin-B. Orexin-A is a peptide of 33 amino acids, and is different from orexin-B with 28 amino acids. In the present study, serum concentrations of orexin-A were measured using a commercially available radioimmunoassay kit (RIK 9600, Peninsula Laboratories, Inc., Belmont, CA, USA). Briefly, an antibody radioimmunoassay using rabbit antiserum specific for recombinant orexin-A and ${ }^{125}$ I-labeled orexin-A as the tracer was used. The assay mixture was composed of a $100 \mu \mathrm{l}$ standard or sample and $100 \mu \mathrm{l}$ antiserum. After overnight incubation at $4{ }^{\circ} \mathrm{C},{ }^{125}$ I-labeled orexin-A with RIA buffer $(0.05 \mathrm{~mol} / \mathrm{l}$ sodium phosphate $(\mathrm{pH}$ 7.4), $\mathrm{NaCl}, \mathrm{NaN}_{3}, \mathrm{BSA}$ and $0.1 \%$ Triton $\mathrm{X}-100$ ) was added. The desired range for the assay was between 10000 and 15000 c.p.m. per $100 \mu$ l. The mixture was again incubated overnight at $4{ }^{\circ} \mathrm{C}$. Separation of free and bound tracer was achieved by adding $100 \mu \mathrm{l}$ goat anti-rabbit IgG serum and normal rabbit serum (both Scantibodies Lab., Santee, CA, USA). After $90 \mathrm{~min}$ at room temperature, the bound tracer was precipitated by centrifugation (at $4{ }^{\circ} \mathrm{C}, 20 \mathrm{~min}$ at $1700 \boldsymbol{g})$, the supernatant was carefully aspirated off, and the radioactivity was measured in a $\gamma$-counter (Wallac Oy, Turku, Finland). This RIA possesses an assay sensitivity of $18 \mathrm{pg} / \mathrm{ml}$ and the intra- and interassay coefficients of variation were $5 \%$ and $20 \%$ respectively. No cross reactivity was detected with orexin-B, NPY, $\alpha$-melanocyte stimulating hormone, or leptin. Plasma NPY concentrations were also determined using a commercially available radioimmunoassay kit (RIK 7180, Peninsula Laboratories, Inc.). No cross reactivity was found with Peptide YY, insulin, prepro NPY, somatostatin, or vasoactive intestinal peptide. All samples for measuring orexin-A and NPY levels were assayed at the same time.

Plasma leptin values were measured using a newly developed, sensitive ELISA assay as described elsewhere (23). Briefly, aliquots of recombinant human leptin or samples $(100 \mu \mathrm{l})$ were added to the wells of the antibody-coated microplates and incubated for $2 \mathrm{~h}$ (first reaction). After the wells were washed with the washing solution containing $0.5 \mathrm{ml} / \mathrm{l}$ Tween 20 in PBS $(250 \mu \mathrm{l})$, Fab'-enzyme conjugate $(25 \mathrm{ng})$ in assay 
buffer was added. The samples were left standing for $1 \mathrm{~h}$ (second reaction). The wells were aspirated and washed again, and then substrate solution $(100 \mu \mathrm{l})$ was added to each well. After $15 \mathrm{~min}$ incubation (enzyme reaction), stop solution $(50 \mu \mathrm{l})$ was added, and the absorbance at $450 \mathrm{~nm}$ was measured with an ImmunoReader NJ-2000 (Nippon InterMed K.K.). This sensitive ELISA showed good correlation with a commercially available RIA $(r=0.99)$ in determining plasma leptin concentrations. Recovery of exogenously added leptin from plasma samples ranged from $86.1 \%$ to $95.6 \%$ and the dilution curve showed good linearity. The lower working range of the ELISA corresponded to $\sim 23 \mathrm{pg} / \mathrm{ml}$ and $\sim 16 \mathrm{pg} / \mathrm{ml}$ leptin, which is $20-30$ times lower than that of a commercially available RIA kit. No serum interference was observed in leptinfree serum by the ELISA in contrast to the RIA kit. The intra- and interassay coefficients of variation were $\leq 4.0 \%$ and $6.6 \%$ respectively.

\section{Statistical analysis}

Results were analyzed by ANOVA followed by Bonferroni-adjusted t-test, where appropriate. Correlations between various parameters were calculated by Pearson correlation coefficients. For all analyses, $P=0.05$ is a critical value of significance. Data analysis was performed with StatView 5.0 (SAS Institute Inc, Cary, NC, USA).

\section{Results}

\section{Body weight changes and hormonal and metabolic parameters before, during, and after fasting}

The changes in body weight, body mass index (BMI), and hormonal and metabolic parameters are shown in Table 1.
Body weight and BMI gradually and significantly decreased during the fasting period, and they continued to decrease until the third day of refeeding.

Plasma ACTH concentrations changed in various ways in individual patients during fasting. The mean concentration, however, was not significantly changed compared with the prefasting value. Serum cortisol concentrations, on the other hand, significantly increased during fasting and returned to the prefasting basal value after refeeding started.

Serum insulin and C-peptide rapidly and significantly decreased on the third day of fasting compared with the prefasting concentration and remained lower during fasting. On the 10th day of fasting, however, no significant changes were found in plasma insulin or C-peptide concentrations compared with the prefasting concentrations.

Plasma glucose and $\beta-\mathrm{OH}$-butyrate changed inversely during fasting, as expected. Plasma glucose decreased significantly, whereas $\beta-\mathrm{OH}-$ butyrate increased significantly during fasting. Both returned to the prefasting values by the 3rd day of refeeding.

\section{Serum orexin-A}

Serum orexin-A was significantly increased on the third day of fasting compared with the prefasting concentrations (Fig. 1A, Table 1). It remained higher during fasting, but was significantly decreased to prefasting levels on the third day of refeeding. It was inversely correlated with plasma leptin concentration $(r=-0.345, P=0.0142)$ and $\log$ leptin $(r=-0.449, P=0.0011)$ (Fig. 2). Negative correlations with glucose $(r=-0.454, P=0.0011)$ and insulin $(r=-0.273, P=0.055)$, and a positive correlation with $\beta-\mathrm{OH}$-butyrate $(r=0.560$, $P<0.0001)$ were found. Serum orexin-A was not significantly correlated with BMI.

Table 1 Changes in body weight, BMI, and hormonal and metabolic parameters before, during and after fasting. Results are the means \pm S.E.M. of 10 patients ( $n=8$ for $10^{\text {th }}$ day of fasting).

\begin{tabular}{|c|c|c|c|c|c|c|}
\hline & \multirow[b]{2}{*}{ Before } & \multicolumn{3}{|c|}{ During fasting } & \multicolumn{2}{|c|}{ Refeeding } \\
\hline & & $3^{\text {rd }}$ day & $7^{\text {th }}$ day & $10^{\text {th }}$ day & $3^{\text {rd }}$ day & $7^{\text {th }}$ day \\
\hline Body weight (kg) & $48.0 \pm 2.0$ & $46.2 \pm 2.1^{\star *}$ & $44.6 \pm 1.9^{* \star}$ & $44.4 \pm 2.2^{\star \star}$ & $43.9 \pm 1.9^{\star \star}$ & $46.1 \pm 3.0$ \\
\hline BMI $\left(\mathrm{kg} / \mathrm{m}^{2}\right)$ & $19.9 \pm 0.8$ & $19.2 \pm 0.8^{* *}$ & $18.5 \pm 0.8^{* *}$ & $18.4 \pm 1.0^{\star \star}$ & $18.3 \pm 0.8^{\star *}$ & $18.9 \pm 1.2$ \\
\hline ACTH (pmol/l) & $4.8 \pm 0.6$ & $4.8 \pm 0.7$ & $3.3 \pm 0.5$ & $3.4 \pm 0.8$ & $3.7 \pm 0.5$ & $4.5 \pm 0.7$ \\
\hline Cortisol (nmol/l) & $313.4 \pm 27.8$ & $469.0 \pm 47.3^{\star *}$ & $448.1 \pm 34.3^{*}$ & $450.0 \pm 46.9^{*}$ & $369.7 \pm 43.5$ & $366.0 \pm 48.2$ \\
\hline Insulin (pmol//) & $51.9 \pm 4.8$ & $30.3 \pm 1.6^{\star \star}$ & $34.7 \pm 3.0^{\star}$ & $40.3 \pm 5.6$ & $50.8 \pm 6.2$ & $62.8 \pm 7.2$ \\
\hline C-peptide (nmol/l) & $0.35 \pm 0.05$ & $0.16 \pm 0.02^{\star \star}$ & $0.17 \pm 0.03^{*}$ & $0.25 \pm 0.06$ & $0.40 \pm 0.06$ & $0.43 \pm 0.07$ \\
\hline Glucose $(\mathrm{mmol} / \mathrm{l})$ & $4.66 \pm 0.15$ & $3.62 \pm 0.25^{\star \star}$ & $3.66 \pm 0.17^{\star \star}$ & $3.83 \pm 0.18^{\star \star}$ & $4.59 \pm 0.15$ & $4.64 \pm 0.12$ \\
\hline$\beta$-OH-butyrate $(\mu \mathrm{mol} / \mathrm{l})$ & $73 \pm 31$ & $1844 \pm 335^{\star \star}$ & $3329 \pm 222^{\star *}$ & $3445 \pm 398^{\star *}$ & $696 \pm 150$ & $118 \pm 28$ \\
\hline Orexin-A (pg/ml) & $29.9 \pm 1.6$ & $38.9 \pm 4.2^{\star}$ & $43.4 \pm 2.9^{\star \star}$ & $47.9 \pm 5.4^{\star \star}$ & $33.8 \pm 1.7$ & $33.4 \pm 3.7$ \\
\hline NPY (pg/ml) & $231.1 \pm 15.8$ & $202.2 \pm 13.6$ & $200.0 \pm 13.9$ & $188.6 \pm 8.0$ & $216.7 \pm 17.5$ & $232.9 \pm 17.7$ \\
\hline Leptin (pg/ml) & $4991.3 \pm 1132.1$ & $1677.8 \pm 540.6^{\star \star}$ & $1322.3 \pm 261.3^{\star \star}$ & $1260.5 \pm 393.9^{\star \star}$ & $1842.2 \pm 433.7^{\star \star}$ & $3600.4 \pm 1215.8$ \\
\hline
\end{tabular}

${ }^{\star} P<0.05,{ }^{\star \star} P<0.01$, a significant difference from the corresponding pre-fasting value. Differences between means were tested by Bonferroni-adjusted $t$-test after ANOVA. 

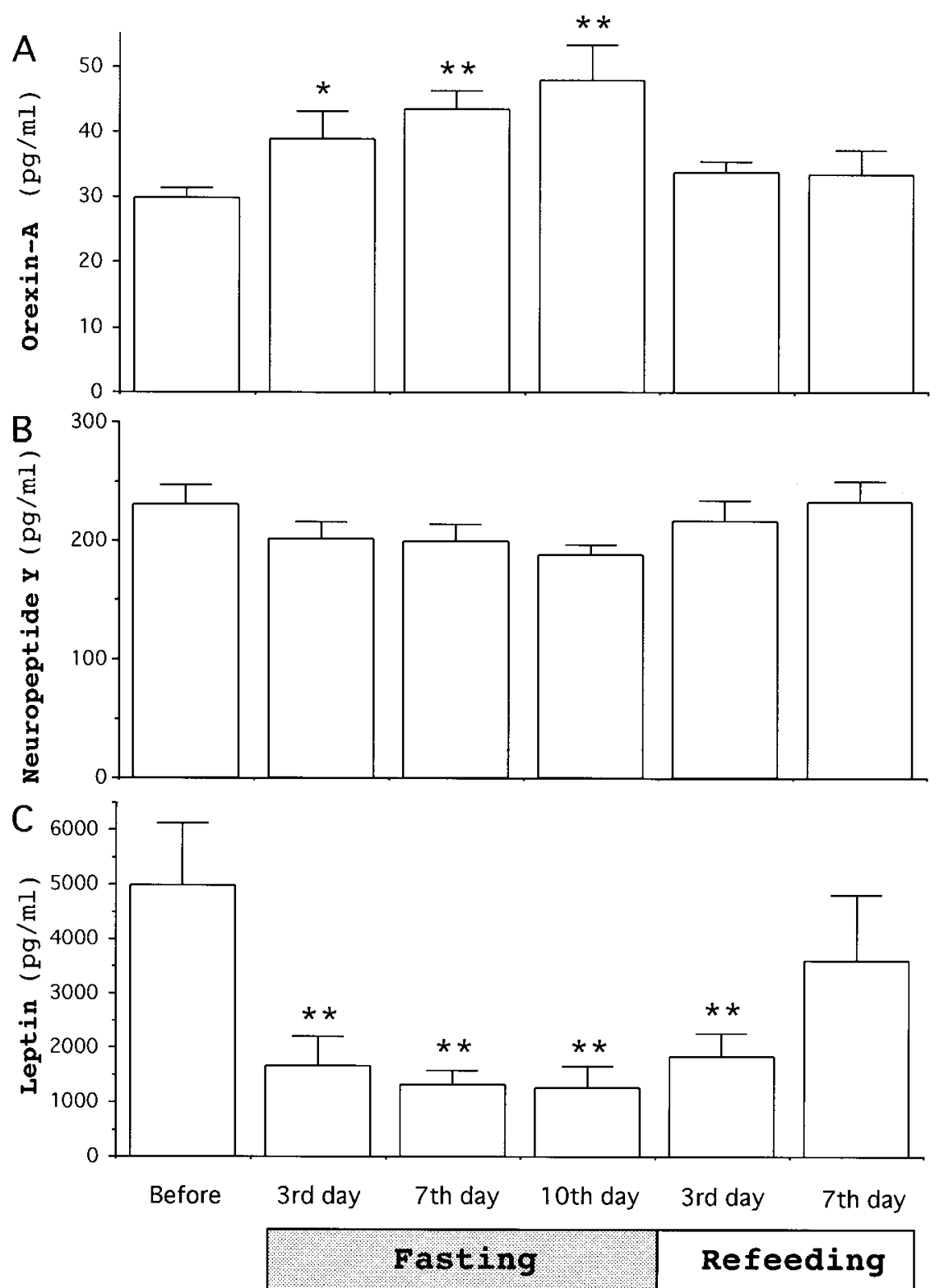

Figure 1 (A) Serum orexin-A concentration was significantly increased during fasting compared with the prefasting value and returned to the basal value after refeeding started. (B) The time course of plasma neuropeptide $Y$ concentration before, during and after fasting. The mean concentration was not significantly changed during or after fasting compared with the prefasting value. (C) Plasma leptin significantly decreased and remained lower during fasting and on the 3rd day of refeeding compared with the prefasting value. Compared with the corresponding fasting value, it increased significantly on the 3rd day of refeeding (vs day 7 of fasting, $P<0.05$; vs day 10 of fasting, $P<0.05)$. The significance level for the difference in the means from the value before fasting was made by ANOVA with Bonferroni-adjusted $t$-test (orexin-A, $\mathrm{F}=3.888, P=0.0054$; NPY, $\mathrm{F}=1.333, P=0.2686$; leptin, $\mathrm{F}=4.337, P=0.0025$ ). ${ }^{\star} P<0.05$, ${ }^{* *} P<0.01$

\section{Plasma NPY}

The mean concentration of plasma NPY was slightly decreased but not significantly changed compared with the prefasting value (Fig. 1B, Table 1). No correlation was found between plasma NPY concentration and either serum orexin-A or plasma leptin concentration. Furthermore, no relationship was found between plasma NPY concentration and BMI, glucose, Cpeptide, or insulin concentration. The only positive correlation was with $\beta-\mathrm{OH}$-butyrate concentration $(r=$ $0.290, P=0.0408$ ). 


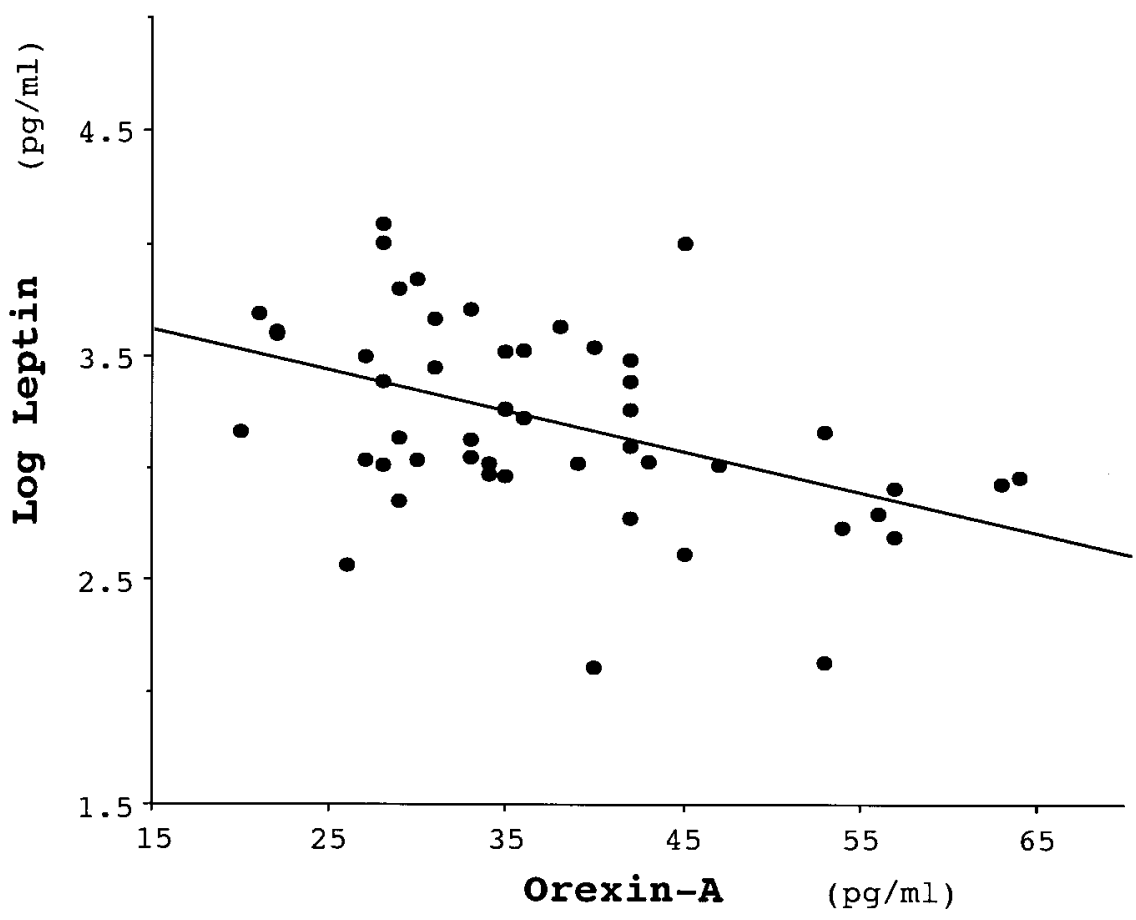

Figure 2 Correlation between serum orexin-A and plasma log leptin concentrations in ten patients before, during and after fasting. There was a significant negative correlation $(r=-0.449, P=0.0011)$ between orexin-A and log leptin values. The solid line indicates the linear regression line: $y=-0.018 x+3.877$.

\section{Plasma leptin}

Plasma leptin was significantly decreased on the third day of fasting compared with the prefasting concentration, and it remained lower throughout the fasting period (Fig. 1C, Table 1). Although the mean plasma leptin concentration was still lower on the third day of refeeding compared with the prefasting value $(P<0.01)$, it was significantly increased on the third day of refeeding compared with the corresponding fasting values (vs seventh day of fasting, $n=10$, $P<0.05$; vs tenth day, $n=8, P<0.05)$. It returned to the prefasting values on the seventh day of refeeding.

Plasma leptin concentration was significantly correlated with BMI $(r=0.599, P<0.0001)$. There were also significant correlations with insulin $(r=0.527$, $P<0.0001), \quad$ C-peptide $(r=0.629, \quad P<0.0001)$, glucose $(r=0.488, P=0.0002)$, and $\beta$-OH-butyrate $(r=-0.455, \quad P=0.0005)$ throughout the study period. Whereas plasma leptin showed no significant correlation with ACTH, there were inverse correlations between the leptin and cortisol concentrations $(r=-0.362, P=0.0125)$.

\section{Discussion}

Starvation is a threat to survival and to the homeostasis of the internal milieu. Therefore, numerous physiological systems have developed to defend against it. Although the sample size is rather small, this is the first study comparing orexin-A, leptin, and NPY concentrations simultaneously with other metabolic and nutritional factors during and after fasting in humans.

In the present study, the finding that fasting induces a significant decrease in peripheral leptin confirmed previous studies (15-17). The significant, positive correlation of leptin with glucose, insulin, and Cpeptide, and the negative correlation with $\beta$-hydroxybutyrate are also consistent with recent studies (17). Furthermore, leptin concentrations showed a negative correlation with circulating serum cortisol concentrations, indicating a role for leptin in stress regulation $(24,25)$. The detection limit for plasma leptin was much improved in the present study by the use of a sensitive ELISA (23) and we were therefore able to distinguish the changes in the lower range. In fact, plasma leptin was low, but significantly increased on the 3rd day of refeeding accompanied by a decrease in serum cortisol, even though body weight continued to decrease until the third day of refeeding. This confirms that the change in leptin appears to dysregulate or uncouple from body weight itself $(16,26)$ and that it is more related to other endocrine and nutritional factors during fasting $(15,24,27)$. Leptin plays, at least in part, an important role in the metabolic adaptation to acute starvation. 
No significant changes in plasma NPY concentrations and no interrelations with metabolic factors, except $\beta$-OH-butyrate, or with leptin or insulin concentrations were found during fasting. Animal studies of fasting found increases in hypothalamic NPY mRNA (27); however, the exact nature of the relationship between central and peripheral measures of NPY is poorly understood at present (28). Further, in response to various psychological and/or physical factors, both an increase $(18,19)$ and a decrease $(20)$ in circulating NPY concentration have been reported in correlation with the noradrenaline release. Although NPY co-localizes with noradrenaline in sympathetic nerves (29) and fasting may suppress the activity of the sympathetic nervous system $(30,31)$, the present measurements indicate that changes in circulating NPY levels are irrelevant to the energy status during fasting.

Orexin is a newly discovered peptide in the hypothalamus and a strong regulator of food intake (10). Recently, Kirchgessner and Liu found a subset of orexin-containing neurons in the gut in animals expressing functional orexin receptors (21). They observed a functional response to food status in these cells, possibly indicating a more intimate role in regulating energy metabolism than it does in the central nervous system (21). Therefore, we measured peripheral orexin-A, a 33-amino acid peptide which has a more potent and prolonged effect on appetite compared with orexin-B, a 28-amino acid peptide (10), during fasting. Interestingly, serum orexin-A concentrations increased significantly, and had a negative correlation with plasma leptin concentrations. Furthermore, in contrast to the leptin findings, significant inverse relationships were found between orexin-A and glucose, insulin, and C-peptide concentrations. In addition, there was no significant correlation between BMI and orexin-A in a cohort of normal subjects (data not shown). Although it is possible that changes in orexin-A release from the gut could be due to a marked erosion of the gastrointestinal mucosae during fasting, these findings are consistent with the findings in rats that orexin appeared to participate in a short-term regulation of energy homeostasis in response to falls in glucose which was terminated after food ingestion (32). It is also possible that there is some direct effect of circulating orexin-A on the peripheral gut tissues, as orexin excited secretomotor neurons in the guinea pig submucosal plexus, and increased motility (21). Since orexin-A rapidly crosses the blood-brain barrier and reaches brain tissue (33), a peripheral increase in orexin-A might, at least in part, also contribute to appetite control and to energy expenditure in humans.

On the other hand, fasting is also a potent psychological and physiological stressor (3). As previously reported, serum cortisol concentrations increased significantly (3-5) and have an inverse relationship with plasma leptin concentrations during fasting $(8,27)$. Plasma NPY concentrations, on the other hand, did not show any correlation with serum cortisol concentrations. This finding is consistent with the dissociation between cortisol and NPY under various stresses $(34,35)$, and the finding that adrenalectomy revealed no effect on plasma NPY concentrations (36). As to orexin-A, no direct correlation was found with cortisol concentrations in the present study. Since i.c.v. injection of orexin activated the HPA axis $(37,38)$, an increase in orexin-A concentration during fasting might possibly contribute to the activation of the HPA axis. It is puzzling, however, that despite marked increases in cortisol levels during fasting, ACTH concentrations changed in various ways in individual subjects. This is probably because the serum ACTH-cortisol feedback system had been altered under the stress condition, even though cortisol levels remained high (39). Therefore, the interrelation of orexin-A with the HPA axis during fasting seems weaker when compared with that of leptin. Although the mechanism(s) by which fasting therapy improved the symptoms of psychosomatic disorders is still unknown, fasting therapy might activate the HPA axis, at least in part, by changes in such peptides as orexin-A and/or leptin, consequently improving response to stress in daily life. Future study is warranted to clarify the precise mechanism(s).

In conclusion, the present study indicates that fasting inversely affects peripheral orexin-A and leptin concentrations, which are correlated with metabolic and nutritional state in humans.

\section{Acknowledgements}

We thank Dr Y Numata (Department of Analytical Chemistry, Developmental Research Laboratories, Shionogi Co. Ltd, Osaka, Japan) for performing the leptin assay. This work was supported by a grant-in-aid for scientific research from the Ministry of the Health and Welfare of Japan.

\section{References}

1 Wing ED, Stanko RT, Winkelstein A \& Adibi SA. Fasting enhanced immune effector mechanisms in obese subjects. American Journal of Medicine 198375 91-96.

2 Yamamoto H, Suzuki J \& Yamauchi Y. Psychophysiological study on fasting therapy. Psychotherapy and Psychosomatics 197932 229-240.

3 Pirke KM \& Ploog D. Biology of human starvation. In Handbook of Eating Disorders edn 1, part 1, pp 79-102. Eds PJV Beumont, G Burrows \& R Casper. Amsterdam: Elsevier, 1987.

4 Komaki G, Tamai H, Sumioki H, Mori T, Kobayashi N, Mori K et al. Plasma beta-endorphin during fasting in man. Hormone Research 199033 239-243.

5 Komaki G, Kanazawa F, Sogawa H, Mine K, Tamai H, Okamura S et al. Alterations in lymphocyte subsets and pituitary-adrenal gland-related hormones during fasting. American Journal of Clinical Nutrition 199766 147-152. 
6 Zakowski SG, McAllister CG, Deal M \& Baum A. Stress, reactivity, and immune function in healthy men. Health Psychology 1992 $11223-232$.

7 Bachen EA, Manuck SB, Cohen S, Muldoon MF, Raible R, Herbert TB et al. Adrenregic blockade ameliorates cellular immune responses to mental stress in humans. Psychosomatic Medicine 199557 366-372.

8 Flier JS. What's in a name? In search of leptin's physiologic role. Journal of Clinical Endocrinology and Metabolism $1998 \mathbf{8 3}$ 1407-1413.

9 Criscione L, Rigollier P, Batzl-Hartmann C, Rueger H, StrickerKrongrad A, Wyss $\mathrm{P}$ et al. Food intake in free-feeding and energydeprived lean rats is mediated by the neuropeptide $\mathrm{Y} 5$ receptor. Journal of Clinical Investigation $1998 \mathbf{1 0 2} 2136-2145$.

10 Sakurai T, Amemiya A, Ishii M, Matsuzaki I, Chemelli RM, Tanaka $\mathrm{H}$ et al. Orexins and orexin receptors: a family of hypothalamic neuropeptides and $\mathrm{G}$ protein-coupled receptors that regulate feeding behavior. Cell 199892 573-585.

11 Horvath TL, Diano S \& van den Pol AN. Synaptic interaction between hypocretin (orexin) and neuropeptide $\mathrm{Y}$ cells in the rodent and primate hypothalamus: a novel circuit implicated in metabolic and endocrine regulations. Journal of Neuroscience $1999191072-1087$.

12 Mercer JG, Hoggard N, Williams LM, Lawrence CB, Hannah LT, Morgan PJ et al. Coexpression of leptin receptor and preproneuropeptide $\mathrm{Y}$ mRNA in arcuate nucleus of mouse hypothalamus. Journal of Neuroendocrinology 19968 733-735.

13 Lopez M, Seoane L, Garcia MC, Lago F, Casanueva FF, Senaris R et al. Leptin regulation of prepro-orexin and orexin receptor mRNA concentrations in the hypothalamus. Biochemical and Biophysical Research Communications $200026941-45$.

14 Remesar X, Rafecas I, Fernandez-Lopez JA \& Alemany M. Is leptin an insulin counter-regulatory hormone? FEBS Letters $1997 \mathbf{4 0 2}$ 9-11.

15 Maffei M, Halaas J, Ravussin E, Pratley RE, Lee GH, Zhang Y et al. Leptin levels in human and rodent: measurement of plasma leptin and $o b$ RNA in obese and weight-reduced subjects. Nature Medicine 19951 1155-1161.

16 Weigle DS, Duell PB, Connor WE, Steiner RA, Soules MR \& Kuijper JL. Effect of fasting, refeeding, and dietary fat restriction on plasma leptin concentrations. Journal of Clinical Endocrinology and Metabolism $1997 \mathbf{8 2}$ 561-565.

17 Kolaczynski JW, Considine RV, Ohannesian J, Marco C, Opentanova I, Nyce MR et al. Responses of leptin to short-term fasting and refeeding in humans. Diabetes $1996 \mathbf{4 5} 1511-1515$

18 Morris MJ, Russell AE, Kapoor V, Cain MD, Elliott JM, West MJ et al. Increases in plasma neuropeptide $\mathrm{Y}$ concentrations during sympathetic activation in man. Journal of the Autonomic Nervous System 198617 143-149.

19 Lundberg JM, Martinsson A, Hemsen A, Theodorsson-Norheim E, Svedenhag J, Ekblom B et al. Co-release of neuropeptide Y and catecholamines during physical exercise in man. Biochemical and Biophysical Research Communications 1985133 30-36.

20 Rasmusson AM, Hauger RL, Morgan CA, Bremner JD, Charney DS \& Southwick SM. Low baseline and yohimbinestimulated plasma neuropeptide Y (NPY) concentrations in combat-related PTSD. Biological Psychiatry 200047 526-539.

21 Kirchgessner AL \& Liu M. Orexin synthesis and response in the gut. Neuron 199924 941-951.

22 Komaki G, Tamai H, Mori T, Nakagawa T \& Mori S. Changes in serum angiotensin-converting enzyme in acutely starved nonobese patients: a possible dissociation between angiotensinconverting enzyme and the thyroid state. Acta Endocrinologica $198811845-50$.

23 Imagawa K, Matsumoto Y, Numata Y, Morita A, Kikuoka S, Tamaki $\mathrm{M}$ et al. Development of a sensitive ELISA for human leptin using monoclonal antibodies. Clinical Chemistry $19984 \mathbf{4}$ 2165-2171.

24 Heiman ML, Ahima RS, Craft LS, Schoner B, Stephens TW \& Flier JS. Leptin inhibition of the hypothalamic-pituitary-adrenal axis in response to stress. Endocrinology 1997138 3859-3863.

25 Bornstein SR, Uhlmann K, Haidan A, Ehrhart-Bornstein M \& Scherbaum WA. Evidence for a novel peripheral action on leptin as a metabolic signal to the adrenal gland: leptin inhibits cortisol release directly. Diabetes $1997 \mathbf{4 6} 1235-1238$.

26 Eckert ED, Pomeroy C, Raymond N, Kohler PF, Thuras P \& Bowers CY. Leptin in anorexia nervosa. Journal of Clinical Endocrinology and Metabolism 199883 791-795.

27 Ahima RS, Prabakaran D, Mantzoros C, Qu D, Lowell B, MaratosFlier $\mathrm{E}$ et al. Role of leptin in the neuroendocrine response to fasting. Nature $1996 \mathbf{3 8 2} 250-252$.

28 Morgan CA, Wang S, Southwick SM, Rasmusson A, Hazlett G, Hauger RL et al. Plasma neuropeptide-Y concentrations in humans exposed to military survival training. Biological Psychiatry 200047 902-909.

29 Wahlestedt C \& Reis DJ. Neuropeptide Y-related peptides and their receptors: are the receptors potential therapeutic drug targets? Annual Review of Pharmacology and Toxicology 1993 32 309-352.

30 Gohler L, Hahnemann T, Michael N, Oehme P, Steglich HD, Conradi E et al. Reduction of plasma catecholamines in humans during clinically controlled severe underfeeding. Preventative Medicine 200030 95-102.

31 Young JB \& Landsberg L. Suppression of sympathetic nervous system during fasting. Obesity Research 1997 5 646-649.

32 Cai XJ, Widdowson PS, Harrold J, Wilson S, Buckingham RE, Arch JR et al. Hypothalamic orexin expression: modulation by blood glucose and feeding. Diabetes 199948 2132-2137.

33 Kastin AJ \& Akerstrom V. Orexin A but not orexin B rapidly enters brain from blood by simple diffusion. Journal of Pharmacology and Experimental Therapeutics $1999289219-223$.

34 Hanson ES, Levin N \& Dallman MF. Elevated corticosterone is not required for the rapid induction of neuropeptide $\mathrm{Y}$ gene expression by an overnight fast. Endocrinology $1997 \mathbf{1 3 8}$ 1041-1047.

35 Guidi L, Tricerri A, Vangeli M, Frasca D, Riccardo Errani A, Di Giovanni A et al. Neuropeptide Y plasma concentrations and immunological changes during academic stress. Neuropsychobiology 199940 188-195.

36 Bernet F, Dedieu JF, Laborie C, Montel B \& Dupouy JP. Circulating neuropeptide Y (NPY) and catecholamines in rat under resting and stress conditions. Arguments for extra-adrenal origin of NPY, adrenal and extra-adrenal sources of catecholamines. Neuroscience Letters $1998 \mathbf{2 5 0}$ 45-48.

37 Ida T, Nakahara K, Murakami T, Hanada R, Nakazato M \& Murakami N. Possible involvement of orexin in the stress reaction in rats. Biochemical and Biophysical Research Communications 2000270 318-323.

38 Kuru M, Ueta Y, Serino R, Nakazato M, Yamamoto Y, Shibuya I et al. Centrally administered orexin/hypocretin activates HPA axis in rats. Neuroreport 200011 1977-1980.

39 Chrousos GP, Schuermeyer TH, Doppman J, Oldfield EH, Schutte HM, Gold PM et al. Clinical application of corticortopinreleasing factor. Annals of Internal Medicine 1985102 344-358.

Received 9 November 2000

Accepted 12 February 2001 